\title{
A Human Factors Based User Interface Design
}

\author{
Harald Reiterer
}

German National Research Center for Computer Science (GMD), Institute for Applied Information Technology, Human-Computer Interaction Research Division, PO. Box 1316 D-53731 St. Augustin

Phone: +49 2241 14-2729 Fax: +49 2241 14-2618 Mail: reiterer@gmd.de and

University of Vienna, Institute for Applied Computer Science and Information Systems, Liebiggasse 4/3-4, A-1010 Vienna

\begin{abstract}
This paper reports first results of the GMD project "User Interface Design Assistance (IDA)". The objective of this project is to develop computer based design aid tools for a buman factor based user interface design. The reasons for concentrating on human factors are their increasing importance in the new European Economic Area and the lack of knowledge of the designers in the area of human factors. The design aid tools are integrated in a user interface management system (UIMS) to support the designers during the development process. The aim is to impart human factors knowledge for innovative user interfaces (e.g. object-oriented graphical interfaces; 3-D user interfaces; hypermedia user interfaces) to the designers. This will be done with the help of design aid tools, like a composition tool, a tutoring tool and a quality assurance tool. They are presented in some detail. First results have shown, that it is principally possible to realise such design aid tools.
\end{abstract}

\section{The Increasing Importance of Human Factors Based User Interface Design}

One reason for the increasing importance of human factors based user interface design is the new European Economic Area (EEA, consisting of EC and EFTA). To establish common working conditions for visual display terminal (VDT) users, the European Community published a "directive concerning the minimum safety and health requirements for VDT workers" [13]. The national governments of the EC members have to transform this directive into national law. In this process the European standardisation activities of the CEN (Comité Européen de Normalisation) and the international standardisation activities of the ISO (International Organisation for Standardisation) concerning ergonomic requirements for VDTs will have great influence. Especially the ISO standard 9241 "Ergonomic requirements for office work with VDTs" [22] (CEN 29241) plays an important role [8]. In the future this standard will often be an integral part of software requirements specification. 
Therefore software designer will have to take the requirements and principles of this standard into consideration.

Does the software designer know how to apply standards like the ISO 9241 in the design process? Empirical results have shown that most of the software designers have no or only very limited knowledge about human factors $[2,3,31]$. Therefore most of them were not able to apply standards from the area of human factors in the design process. In Beimel et al. [3] designers were asked what kind of support to they prefer to overcome their lack of human factors expert knowledge. A great amount of them said that they would prefer computer based design aids which should be integrated in their design tools (e.g. interface builder, UIMS). What they won't like is "paperware", e.g. manuals or technical reports with a great amount of written style guides or guidelines. Some other authors come to very similar results. They defined some "success factors" for the efficient use of standards and style guides like:

- "... having development tools that support implementation of interfaces that follow the standard including concrete examples of correctly designed interfaces" [46]

- "... the interface style needs to be carried in the examples, facilitated by tool kits, illustrated by interactive demos or well-formed applications, and supported by iterative usability testing." [45],

- "Our most valuable weapons in the arena of fast-paced design and development are our skills and tools for turning design ideas into prototypes of the user interface ..." [32].

So software designers need excellent tools for user interface design, especially for graphical and hypermedia user interfaces. These tools allow the designer to concentrate on the design process and on the quality of the design results, e.g. usability. Tools as for example User Interface Management Systems (UIMS) help the designer to specify, design, prototype, implement, execute, evaluate, modify, and maintain user interfaces. UIMSs are to interface development what CASE tools are to development of application components [19]. The big difference from UIMS to other tools like user interface tool kits and interface builders is that they support the designer during the construction of the presentation layer (static component) as well as during the definition of the dialogue scripts (dynamic component). Therefore they consist of WYSIWYG-Editor for the presentation layout and a script editor for the dialogue flow. Normally they have the availability to simulate the results (user interface prototype without any application code), so that the designer can use a prototyping approach during the design of the user interface. The handling of UIMSs is easy in comparison with other user interface design tools (e.g. tool kits) or conventional programming language, so that also non programmers like graphic designers or human factors experts could use them during the user interface design. This fact opens the opportunity to carry out user interface design activities with a team of different specialists.
How can We Reach a Human Factors Based User Interface Design?

The increasing importance of human factors based user interface design, the lack of uman factors knowledge of the designers and the availability of new user interface design tools were starting points for a new GMD project called "User Interface Design Assistance (IDA)". The objective of this project is to develop design aid tools Design Assistance (IDA)". The objective of this project is to develop design aid tools
for a human factor based user interface design. These design aid tools are integrated in a UIMS to support the designers of innovative user interfaces (e.g. object-oriented graphical interfaces; 3-D user interfaces; hypermedia user interfaces) during the development process. The aim is to impart human factors knowledge for innovative user interfaces to the designers. Therefore the designers should have direct access to the human factors knowledge from their development tool. The presentation of the design knowledge is based on object-oriented, multimedia and knowledge-based techniques. There are multifarious reasons for developing design aid tools for the user interface designers using a UIMS:

- to overcome the lack of human factors knowledge of the designers ("training on the job"),

- to overcome the resistance of the designers reading and using written guide lines, standards, etc. ("new design aids"),

- to reduce the costs developing user interfaces using predefined models ("reusability of software"),

- to assure easy of use of user interfaces ("usability"),

- to guarantee the conformity of the user interface with standards and style guides ("quality assurance").

\subsection{Design Aid Tools for a Human Factors Based User Interface Design}

An important pre-condition for developing computer based design aid tools is to formalise human factors knowledge to allow a computer based presentation. Especially in the area of object-oriented graphical user interfaces the GMD Human-Computer Interaction Research Division has a deep understanding of the necessary design principles and design guidelines, the relevant international standards, the available style guides and the construction and use of evaluation methods for usability testing, e.g. EVADIS $[36,37]$. In the area of 3-D and hypermedia user interfaces the HumanComputer Interaction Research Division is doing much R\&D activities. The results of these R\&D activities and the available experiences in the field of HumanComputer Interaction are the basis for constructing new design principles and guidelines for innovative user interfaces. The human factors knowledge is summarised in a "Human Factors Style Guide", which is the foundation for the computer supported design aid tools. The content of this "Human Factors Style Guide" isn't restricted to commercial available user interface style guide requirements, e.g. OSF/MOTIF Style Guide [34], OPEN LOOK Style Guide [44], IBM Common User Access [20, 21], Microsoft Windows Style Guide [29], SIEMENS/NIXDORF Style Guide [41], APPLE Style Guide [1], NeXT Style 
Guide[33]. The content of our style guide is based on a broader approach and also includes user interface design requirements from the relevant international standards, e.g. ISO 9241 [22], DIN 66234 [11] and literature [e.g. 5, 6, 12, 28, 35, 42]. The focus of the first version of our "Human Factors Style Guide" is on state of the art user interfaces (GUIs). Our research activities during the IDA project we will be the basis to include new design principles and requirements for innovative user interfaces (e.g. 3-D, hypermedia)

Figure 1 shows three design aid tools that assist the designers during the user interface design using a UIMS ("new design aids"). These design aid tools are under development in the IDA project:

- A composition tool to construct innovative user interfaces; based on a library of interaction objects and dialogue scripts [e.g. 24].

- An advice tool to present the human factors knowledge; based on hypermedia documents [e.g. 7, 30], a library of interaction objects and an expert system.

- A quality assurance tool to evaluate the conformance of the user interface with the human factors knowledge; based on an expert system [e.g. 14, 15, 16, 17, 23, $27, .39]$

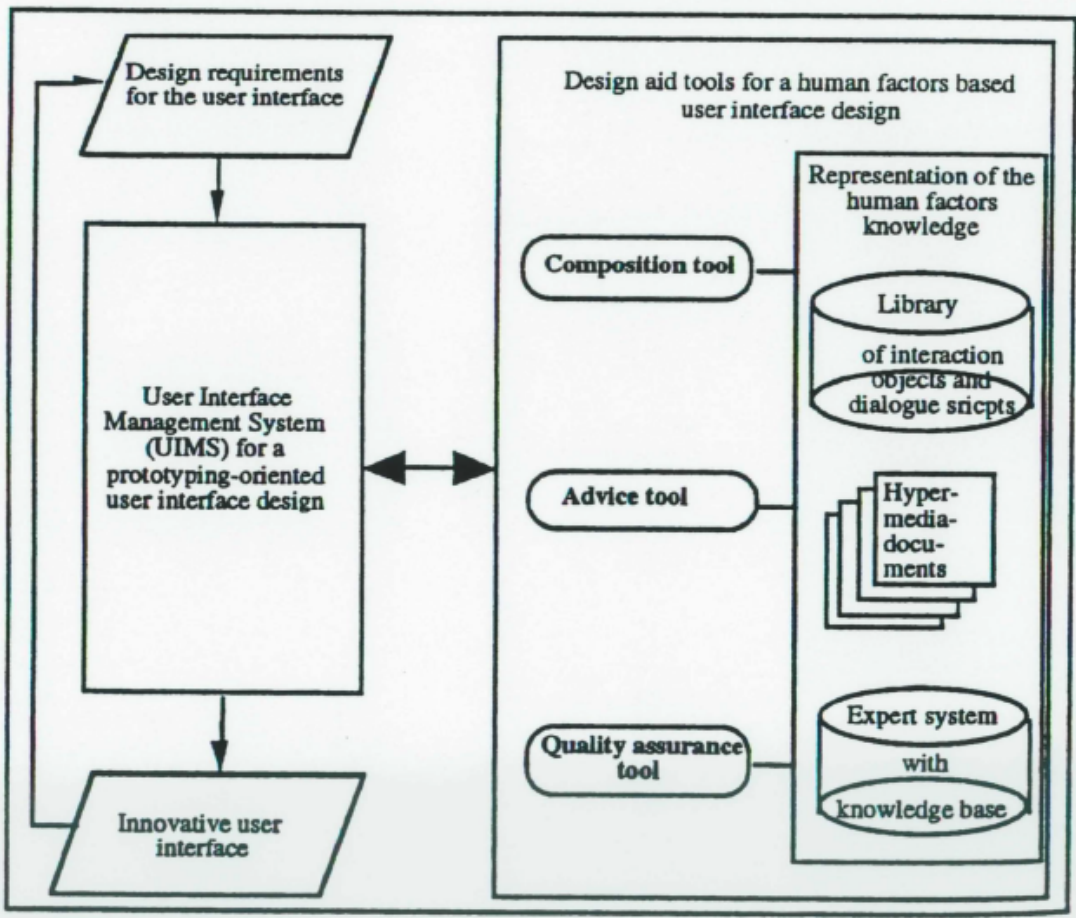

Fig. 1. Design aid tools for a human factor based user interface design
The GMD is starting cooperations with some companies to construct the design aid tools for specific application domains. For this purpose some workshops with members of companies, which are developing software applications and members of companies, which are developing UIMS were arranged. In the realistic context of such application domains the usefulness and usability of the design aid tools will be evaluated.

\subsubsection{Composition Tool}

The composition tool supports the process of constructing the user interface and is based on a library. The content of the library is a collection of predefined generic and domain specific interaction objects and dialogue scripts. The generic interaction objects and dialogue scripts are application independent. Their "look" and "feel" is based on the principles of the "Human Factors Style Guide". The "look" and "feel" of the domain specific interaction objects and dialogue scripts is determined by the application domain, e.g. office system, telecooperation system, CSCW under consideration of the principles of the "Human Factors Style Guide". With the help of an information retrieval component (e.g. structural browser) the designers could search for a relevant generic or domain specific interaction object or dialogue script and use it as a part of the user interface. On the basis of predefined interaction objects and scripts the designers will be able to build the final interface ("reusability of software"). To construct the library an object-oriented mechanism is used. The interaction objects and scripts are designed as models or templates with the UIMS. Each model (object class) can transmit its "look" and "feel" to a specific interaction object (instance of this object class). If the designers chance the "look" and "feel" of a model, each "child" will also chance its "look" and "feel".

In the lead time of this project we have designed a small library with the UIMSs "ISA/Dialog Manager" and "XFaceMaker2" on SUN Workstations and on PCs. The library consists of a small set of interaction objects and scripts based on the Common User Access (CUA) of IBM. It was shown, that it is principally possible to design such a library as a basis for a composition tool.

\subsubsection{Advice and Explanation Tool}

The advice and explanation tool presents the designers the human factors knowledge of the "Human Factors Style Guide" with the help of hypermedia documents and an expert system ("training on the job"). The knowledge is presented in a textual, graphical and animated form in the hypermedia documents. If the designers need support in the area of human factors design, they could get object-sensitive advise. After pressing a push button, they get advise when and how to use a specific interaction object and what should be the "look" and "feel" of this interaction object (advice level of the tutoring tool). If the designers wants deeper information, for example why the "look" and "feel" should be so, they get them in a hypertextual form, e.g. by double clicking the relevant advise information (explanation level of the tutoring tool). So there are two levels of tutoring available: the advise level with short information and the explanation level with deeper information. 
If there exists a relevant model for an interaction object or a script in the library, the designers have the possibility to retrieve it from the library directly in the hypermedia document (link to the library).

A more active form of design support is based on the expert system. If the inference mechanism of the expert system detects some design deficits, a commentary is generated automatically. It shows the designers the analysed deficit and presents them the relevant human factors knowledge in form of a hypermedia document or shows them a relevant interaction object of the library. With the help of these instructions the designers could improve the user interface.

In the lead time of this project we have designed some hypermedia documents with the hypermedia system "DIDOT" (from ISA GmbH, Stuttgart) on SUN Workstations. The content of the hypermedia documents is based on the Common User Access (CUA) of IBM. It was shown, that it is principally possible to design such a tutoring tool

\subsubsection{Quality Assurance Tool}

The quality assurance tool evaluates the conformance of the user interface with human factors knowledge. The knowledge is also based on the "Human Factors Style Guide" and is represented in a knowledge base of an expert system with the help of rules, frames and constraints $[25,40,47]$. The expert system uses the results of the user interface design process as an input and analysis - with the help of the knowledge base and an inference mechanism - the conformance of the user interface with the human factors knowledge ("quality assurance"). The results of the evaluation are comments that show existing deficits and give the designers some advise and explanations to improve the user interface. For this purpose the expert system activates the relevant topics in the tutoring tool or a relevant interaction object in the library. The use of the quality assurance tool is based on the assumption that the designers will use a prototyping approach [18]. After each design cycle the user interface prototype will be evaluated by the quality assurance tool. In the next design cycle all detected deficits can be removed.

In the lead time of this project we have evaluated some expert system shells for the purposes of this project [43]. We use a $\mathrm{C} / \mathrm{C}++$ based expert system shell (ProKappa from Intellicorp), because we have strong performance and portability requirements. We have built a small knowledge base - based on the Common User Access (CUA) to demonstrate the possibility to analyse user interfaces with the help of an expert system. We use an analytic critic approach [15], which checks products with respect to predefined features and effects. In analytical approaches, critics do not need a complete understanding of the product. The quality assurance tool uses a set of rules to identify undesirable features among user interface units, but it does not identify all possible problems within user interface design. Its rule base allows it to criticise user interfaces without exactly knowing the requirements and preferences of the user interface designer.
2.1.4 Integration, Tool Independence and Maintenance of the Design Aid Tools

An important requirement for the project is to present the different design aid tools to the designer in an integrated fashion. For this purpose we have realised a control program called Interface Design Assistant (IDA). The designer could communicate with IDA by the help of a little window, which is permanent placed on the screen (see Figure 2). If the designer wants some help, he or she presses one of the push buttons in the IDA window and gets the support of the selected design aid tool.

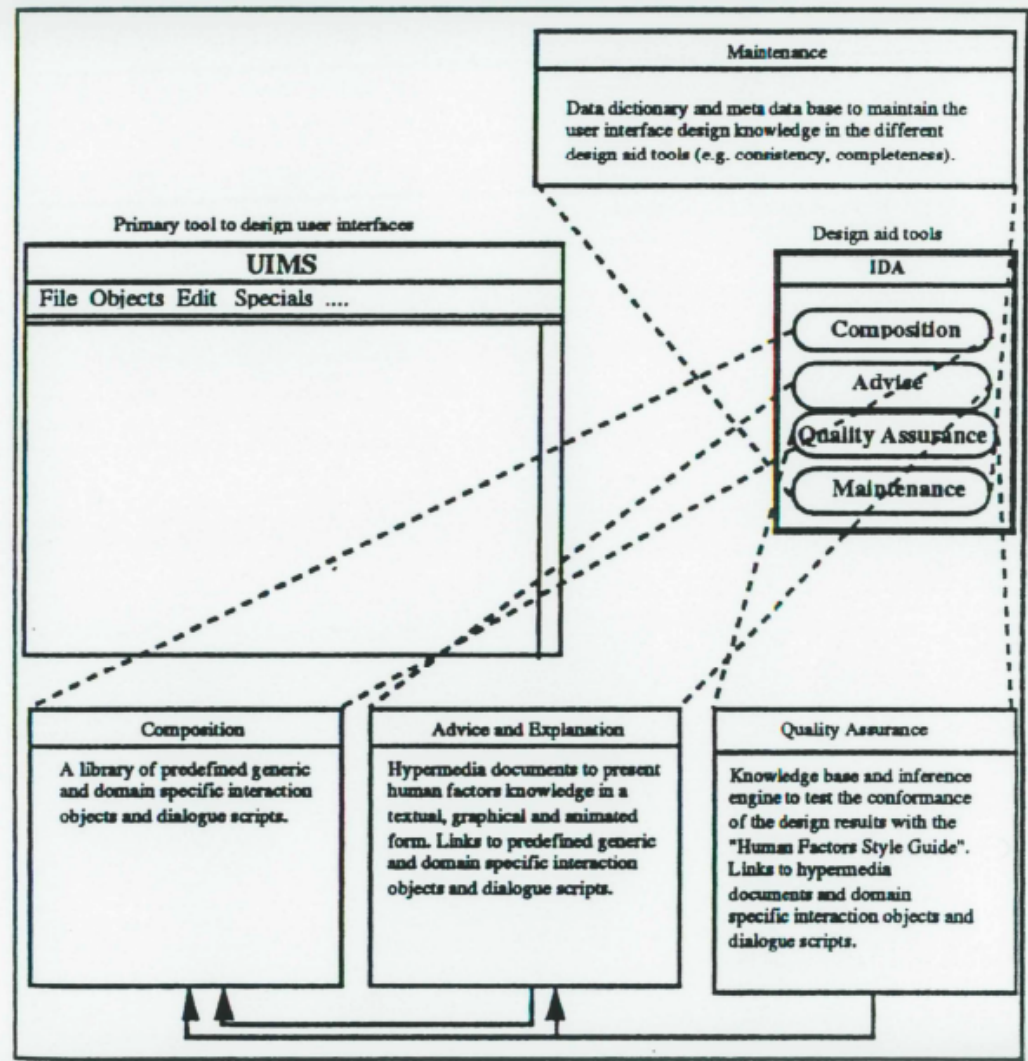

Fig. 2. Integration of the design aid tools

Another important requirement for the project is to realise tool independent design aid tools. In principle it should be possible to integrate the design aid tools in each Cbased UIMS. Therefore different UIMSs will be used as platforms for the integration of the design aid tools, e.g. the "XFaceMaker2" (from Concept asa, Frankfurt and NSL, Paris), the "ISA/Dialog Manager" (form ISA GmbH, Stuttgart). The control program IDA controls the communication and the data flow between the UIMS and all the design aid tools (see Figure 3). So there is a clear interface between different 
UIMSs and the design aid tools. IDA is also responsible for the co-ordination of the different design aid tools. If for example the quality assurance tool detects a deficit IDA got a message to activate a relevant hypermedia document of the tutoring tool at the advise or explanation level. Therefore IDA acts also as an interface between the designer and the different design aid tools.

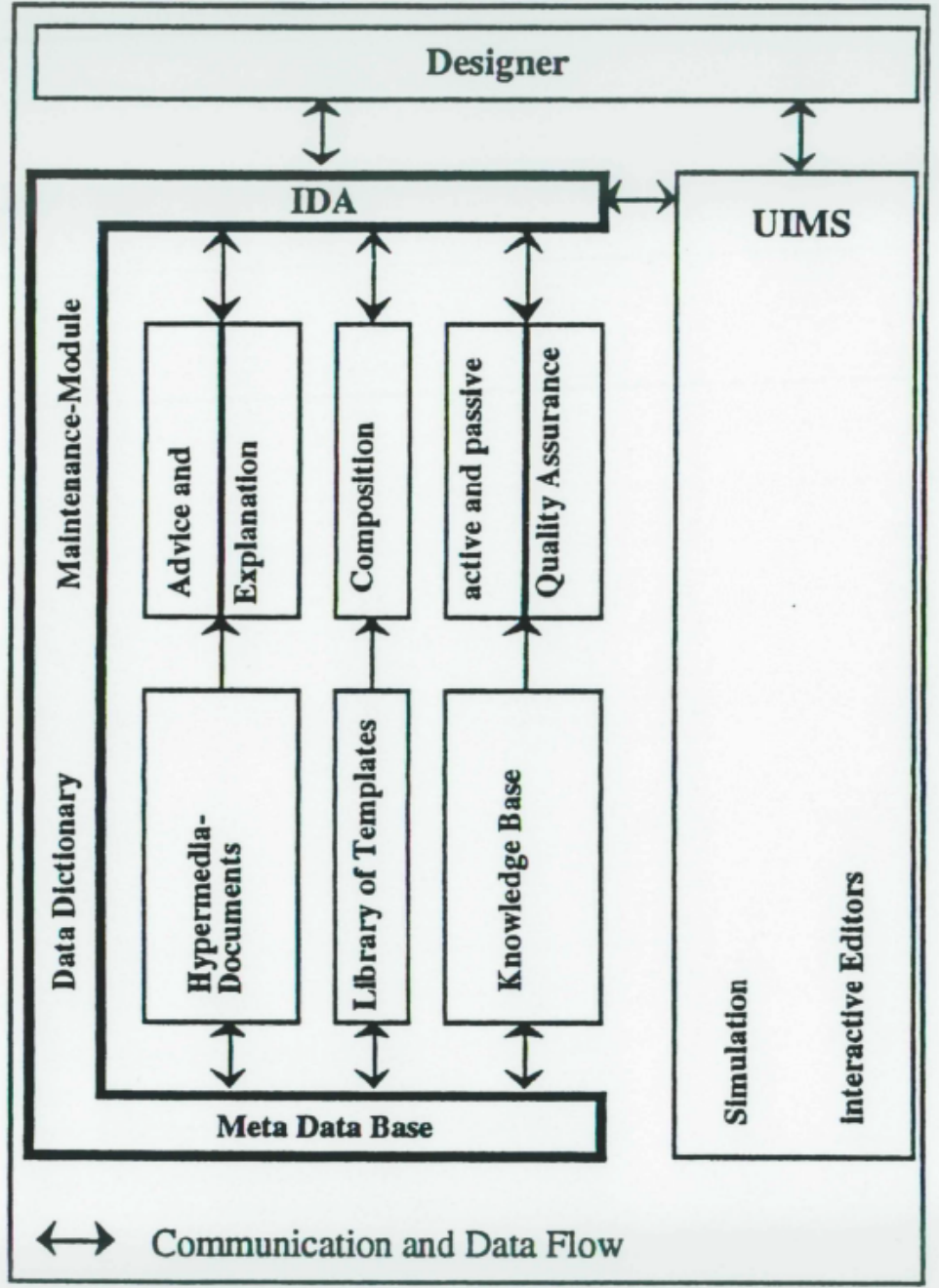

Fig. 3. Tool independence and maintenance of the design aid tools

Another important feature from IDA is the support of the maintenance of the human factors knowledge in the different design aid tools. For this purpose a maintenance module (e.g. a structural browser based on a data dictionary and a meta data base) shows the designer where the knowledge is situated. If chances are necessary or new knowledge should be included the designer could see where the knowledge is located or should be included. In the data dictionary and the meta data base all necessary maintenance information is saved.

\subsection{Integration of the Design Aid Tools in the Software Life-cycle}

It's clear that the user interface design has to be embedded in the software development life-cycle. Today a lot of methods and tools for the application development (e.g. Structured Analysis, Entity-Relationship Model, Structured Analysis and Design Technique, Object-Oriented Method) are available. There are also some special methods for the user interface development (e.g. State Transition Networks, Grammars, Rules and Constraints, Multiagent Techniques). Till now little work has been done to integrate methods of application development and user interface development. We think that the new object-oriented paradigm offers a good chance for such an integration. This assumption is based on the fact, that modern graphical user interfaces (GUIs) also use the object-oriented paradigm (e.g. X-Toolkit). The aim should be to come to one general method for the whole development process. Therefore we are planning to integrate the use of the design aid tools in an objectoriented development life-cycle [e.g. 4, 9, 10,38].

\section{Summary}

In the future a software development environment (e.g. CASE Tool) should contain both, a user interface development environment (UIDE) and an application development environment (ADE). Both environments will contain common tools including programming language compilers, linkers, loaders, debuggers, code analysers, configuration version control managers, and documentation tools. Each development environment will also contain special tools. This paper concentrates on tools and facilities that are unique to the UIDE. In an ideal UIDE the following tools and facilities should be included [26]:

- Tools for specifying user interfaces

- Libraries of reusable software

- Guidelines and advisers

- Tools for evaluating user interfaces

Today commercial UIDE normally includes only tools for specifying user interfaces and in some innovative UIDE you can also find libraries with limited use. In this paper we present some ideas how we can reach a real UIDE including sophisticated libraries of reusable software (composition tool), guidelines and advisers (advice and explanation tool) and tools for evaluating user interfaces (quality assurance tool). We called our tools design aid tools, because their primary focus is not to support the design process (like editors) but to give the designers some advice and evaluation during the design process. We are sure that with the help of such design aid tools the aim "to construct more usable innovative user interfaces" could be reached. 


\section{References}

1. Apple: Macintosh Human Interface Guidelines, Menlo Park, California: Addison

2. Aschersleben G., Zang-Scheucher B.: Der ProzeB der Software-Gestaltung - Ein Bestandsaufnahme in Wissenschaft und Industrie, in: MaaB S., Oberquelle $H$. (Hrsg.): Software-Ergonomie '89, Stuttgart: Teubner, 1989, S.244-253.

3. Beimel J., Hüttner J., Wandke H.: Kenntnisse von Programmierern auf dem Gebiet der Software-Ergonomie: Stand und Möglichkeiten zur Verbesserung. schriftiche Fassung eines Vortrages, gehalten auf der Fachtagung der Seltion Arbeits-, Betriebs und Organisationspsychologie des Berufsugung der Sektion Psychologen "Arbeits- Betriebs- und Organisation Bersuch 27.5.1992 in Bad Lauterbach).

4. Booch E.: Object-Orientied Design, Redwood City, California: Benjam Cummings, 1991.

5. Brown C. M. L.: Human-Computer Interface Design Guidelines, Norwood Ablex Publishing, 1988.

6. Brown J.R., Cunningham S.: Programming the User Interface, Principles and Examples, New York: John Wiley \& Sons, 1989.

7. BRUIT-SAM: An Interface for User Interface Guidelines (HyperCard stack), School of Information \& Computing Sciences, Gold Coast, QLD, 4229, Austrolia: Bond University, 1992

8. Cakir A.: EG-Richlinie für Bildschirmarbeitsplätze, Office Managment, 1-2/1991,

9. Coad P., Yourdan E.: Object Oriented Analysis, Englewood Cliffs: Prentice-Hall, 1991

10. Coad P., Yourdan E.: Object Oriented Design, Englewood Cliffs: Prentice-Hall, $1991 \mathrm{a}$. 11. DIN 66234 Teil 8: Bildschirmarbeitsplätze, Grundsätze der Dialoggestaltung,
Februar 1988.

12. Dumas J.S.: Designing User Interfaces for Software, London: Prentice-Hall, 1988.

13. EEC: European Directive Concerning "The minimum safety and health requirements for work with display sreen equipment", 90/270/EEC

14. Fischer G., Nakakoji K., Ostwald J., Stahl G. Sumner T.: Embedding ComputerBased Critics in the Contexts of Design, INTERCHI '93 Proceedings, April 1993. pp.157-164.

15. Fischer G., Lemke A., Mastaglio T., Morch A.: The Role of Critiquing in Cooperative Problem Solving, in: ACM Transactions on Information Systems, Vol. 9, No. 3, April 1991, p.123-151.

16. Foley J., Kim W., Kovacevic S., Murray K.: UISW - An Intelligent User Interface Design Environment, in: Sullivan J., Tyler S. (eds.): Intelligent User Interfaces, ACM Press, New York, 1991, pp.339-384.
17. Gorny P., Viereck A.: EXPOSE, Ein Software-Ergonomie-Expertensystem, in: Rauterberg M., Ulich E. (Hrsg.): Posterband zur Software-Ergonomie '91, Zürich: IfAP-ETH Zürich, 1991, S.152-161.

18. Hartson H., Smith E.: Rapid prototyping in human-computer interface development, in: Interacting with Computers, vol. 3, no 1, 1991, pp.51-91.

19. Hix D.: Generations of User-Interface Management Systems, in: IEEE Software, September 1990, pp.77-87.

20. IBM: Systems Application Architecture, Common User Access, Guide to User Interface Design, 1991.

21. IBM: Systems Application Architecture, Common User Access, Advanced Interface Design Reference, 1991.

22. ISO 9241: Ergonomic Requirements for Office Work with Visual Display Terminals.

23. Jansen C., Weisbecker A., Ziegler J.: Generation User Interfaces form Data Models and Dialogue Net Specifications, in: INTERCHI'93 Proceedings, pp.418423.

24. Johnson J., Nardi B., Zarmer C., Miller J.: ACE: Building Interactive Graphical Applications, in: Communications of the ACM, April 1993, Vol. 36, No. 4, pp.41-55.

25. Klahr P., Waterman D.: Expert Systems, Techniques, Tools and Applications, Menlo Park, California: Addison-Wesley, 1986

26. Larson J.: Interactive Software, Tools for Building Interactive User Interfaces, Yourdon Press Computing Series, Englewood Cliffs: Prentice Hall Building, 1992.

27. Löwgren J., Nordquist T.: Knowledge-Based Evaluation as Design Support for Graphical User Interfaces, in: CH 92 Porceddings, pp.181-188.

28. Mayhew D. J.: Principles and Guidelines in Software User Interface Design, Englewood Cliffs: Prentice Hall, 1992.

29. Microsoft: The Windows Interface, An Application Design Guide, Microsoft Press, 1992.

30. MITRE: Dynamic Rules for User Interface Design, DRUID 2.0. (HyperCard stack), Bedford: MITRE Corporation, 1991.

31. Molich R., Nielsen J.: Improving a human-computer dialogue, in: Communications of the ACM, vol. 33, no. 3, 1990, pp.338-348.

32. Mulligan R., Altom M., Simkin D.: User Interface Design in the Trenches: Some Tips on Shooting form the HIP, in: CHI '91 Proceedings, pp.232-236.

33. NeXT: Interface Builder Styleguide, Release 2.0, 1991.

34. Open Software Foundation: OSF/MOTIF Style Guide, Revision 1.2, London: Prentice-Hall, 1993.

35. Reiterer H.: Ergonomische Kriterien für die menschengerechte Gestaltung von Bürosystemen - Anwendung und Bewertung, Dissertation, Universität Wien, 1990. 